\title{
Oxidative Stability of Acylated and Hydrogenated Ricinoleates Using Synthetic and Natural Antioxidants
}

\author{
F. Murilo T. Luna, ${ }^{1}$ Davi Costa Salmin, ${ }^{1}$ Vanessa S. Santiago, ${ }^{1}$ Francisco J. N. Maia, ${ }^{2}$ \\ Francisco O. N. Silva, ${ }^{3}$ Selma E. Mazzetto, ${ }^{2}$ and Célio L. Cavalcante Jr. (iD) ${ }^{1}$ \\ ${ }^{1}$ Grupo de Pesquisa em Separações por Adsorção, Núcleo de Pesquisas em Lubrificantes, Departamento de Engenharia Química, \\ Universidade Federal do Ceará, Fortaleza 60.455-900, Brazil \\ ${ }^{2}$ Laboratório de Produtos e Tecnologia em Processos, Departamento de Química Orgânica e Inorgânica, \\ Universidade Federal do Ceará, Fortaleza 60.455-960, Brazil \\ ${ }^{3}$ Laboratório de Bioinorgânica, Departamento de Química Orgânica e Inorgânica, Universidade Federal do Ceará, \\ Fortaleza 60.455-960, Brazil
}

Correspondence should be addressed to Célio L. Cavalcante Jr.; celio@gpsa.ufc.br

Received 4 October 2018; Revised 20 March 2019; Accepted 2 April 2019; Published 14 May 2019

Academic Editor: Beatriz P. P. Oliveira

Copyright (C) 2019 F. Murilo T. Luna et al. This is an open access article distributed under the Creative Commons Attribution License, which permits unrestricted use, distribution, and reproduction in any medium, provided the original work is properly cited.

As increasing environmental policies constrains are imposed, the demand for biodegradable products also increases. Although vegetable oils present some properties that favor its use for formulation of a bio-based lubricant, its poor resistance to oxidation hinders its application as such. In this study, the thermo-oxidative stability of bio-based products was compared to petroleumbased lubricants and vegetable oils through the PetroOXY method. Chemical modifications in the ricinoleic acids were carried out using long-chain alcohols in esterification reactions. Acetates were obtained from ricinoleates with and without hydrogenation steps. Additionally, commercial antioxidants and phenolic compounds (saturated and unsaturated cardanol) obtained from cashew nut shell liquid were added to the synthesized samples with higher induction times. The results show that the chemically modified bio-based products exhibited improved oxidative stability (up to 6 times) and depressed pour point $\left(-42^{\circ} \mathrm{C}\right)$ when compared to pure castor oil. Overall, the addition of antioxidants increased from 6 to 20 times the oxidative stability of the biobased products. Propyl gallate and saturated cardanol showed higher efficiency for retarding the oxidative process of bio-based samples than the commercial antioxidants.

\section{Introduction}

Products with lower toxicity and hence lower propensity for environmental damage have been increasingly demanded. A mineral oil spill requires a significant amount of time and work to stabilize the soil back to normal, causing major negative side effects, such as obstacles to cultivate plants, their reduced growth, and formation of a surface film on the ground that obstructs the proper oxygenation of the soil $[1,2]$. Only around 50 to $60 \%$ of used lubricants are properly recovered and discarded in an environmentally friendly way. Therefore, lubricants originated from biomass could lead to a series of benefits to the environment if they are considered as substitutes to fossil compounds due to their increased degradability [3].
From a technical point of view, it is known that around $90 \%$ of all mineral lubricants being used could be substituted by others formulated to be strongly biodegradable. The use of bio-based lubricants could mean a reduction in environmental pollution. In order to increase the attractiveness of the bio-based lubricants and therefore their market share, their reliability and final price should be improved $[1,4-6]$.

Among available vegetable oils that are candidates to be applied as lubricants, castor oil (Ricinus communis) is of high interest. This vegetable oil (with approximately 90 wt.\% of ricinoleic acid) is currently in the spotlight of the Brazilian government due to the opportunity of its agricultural development in arid areas. Castor is easily cultivated and very resistant to water shortages, being able to prosper even in arid regions. Nevertheless, scientific and 
technological alternatives have to be developed in order to add to obvious social and economic advantages and secure more reliable assurances to the implementation of more extensive applications of castor oil-based lubricants [5, 7].

Vegetable oils are triglycerides formed by saturated, monounsaturated, and polyunsaturated compounds. These oils hold good lubricity and overall protection against wear while keeping stable behavior of their viscosity with respect to temperature changes. However, there are some characteristics that may hinder their indication as lubricants, mainly their low resistance to oxidize $[8,9]$. The main reason for the poor oxidative stability of vegetable oils is the presence of unsaturations in the molecules, which induce high levels of oxygen reactivity [10-12]. The oxidation products will interfere with the original properties of the oil such as total acid number, peroxide index, viscosity, iodine index, polymeric index, and oxidative stability, among others $[13,14]$.

The oxidative stability of vegetable oil derivatives can be improved through the selection of species that may cause reduction of unsaturated fatty acids in the oil. This reduction could be performed by modifications on the oil structure such as transesterification reactions, hydrogenation, and epoxidation. Nevertheless, with or without these modifications, the oxidative stability can still be improved by the addition of antioxidants $[15,16]$.

Antioxidants are substances that can inhibit or retard the oxidative process of a substrate, contributing to the increase of the oxidative stability of fuels, biofuels, lubricants, and polymers, among other products. One of the main class of compounds with antioxidant properties are phenolic compounds, which inhibit the formation or propagation of radical species formed during the oxidation process. The phenolic antioxidants may be classified as two main categories: the synthetic phenolic compounds, as butylated hydroxytoluene (BHT), tert-butylhydroquinone (TBHQ), and propyl gallate $(\mathrm{PG})$, which are obtained from petroleum streams, and natural phenolic compounds as tocopherols, flavonoids, benzoic acid derivatives, and phenolic compounds that may be obtained from Cashew Nut Shell Liquid (CNSL) [17].

The phenolic compounds derived from CNSL have two key advantages: they are obtained from vegetable sources as a by-product of the cashew nut processing industry, being produced in large scale at low cost; they are characterized as a renewable raw material. A typically solvent-extracted CNSL is composed mainly by anacardic acid (60-70\%), cardol (15-20\%), and cardanol (10\%). When obtained as a residue from the industrial roasting shell process, which employs elevated temperatures, anacardic acid experiences a decarboxylation reaction, and CNSL is then considered as technical CNSL, which contains mainly cardanol (60-70\%) [17].

In this context, this study proposes to evaluate the oxidative stability of potential bio-based samples from commercial ricinoleic acid (the major fatty acid present in castor oil) using the PetroOXY method. Accelerated oxidation experiments were carried out for fresh and antioxidant doped samples. The same experimental procedure was applied to mineral lubricant and pure vegetable oil samples to evaluate how the synthesized products compare to those products with extreme characteristics. The effectiveness of the addition of commercial antioxidants and phenolic compounds (saturated and unsaturated cardanol) obtained from cashew nut shell liquid was evaluated for improvement of the oxidative stability of bio-based products.

\section{Materials and Methods}

2.1. Materials. Samples of castor oil (CO) and ricinoleic acid (>95\%) were provided by Miracema-Nuodex (Brazil). Samples of mineral naphthenic oil (MO) were provided by Petrobras (Brazil). 2-Ethyl-1-hexanol (>99.6\%), 1-octanol anhydrous ( $>99 \%)$, boron trifluoride dimethyl etherate, and platinum on activated carbon ( $5 \%$ wt.) were provided by Sigma-Aldrich (USA). Analytical grade reagents (acetic anhydride and ethyl alcohol) were provided by J. T. Baker (USA). Two commercial phenolic antioxidants were used: 2,6-di-tert-butyl-4-methylphenol (DBPC) kindly supplied by Indukern (Brazil) and propyl 3,4,5-trihydroxybenzoate (PG) kindly supplied by Eastman Chemicals (USA). Saturated cardanol (S-CDN) was provided by Sigma-Aldrich (USA). Cashew Nut Shell Liquid (CNSL) was supplied by Amêndoas Do Brasil Ltda (Brazil). Ethyl acetate and hexane were supplied by Vetec Química (Brazil). Hydrogen (>99.95\%), oxygen (>99.5\%), and nitrogen (>90\%) were purchased from White Martins Praxair (Brazil). Column chromatography was run using silica gel 60 , while thin layer chromatography (TLC) was conducted on precoated silica gel polyester sheets (Kieselgel 60 F254, $0.20 \mathrm{~mm}$, Merck, USA). The chemical structures of studied antioxidants are presented in Figure 1.

2.2. Synthesis Procedures. Samples were synthesized using ricinoleic acid as the raw material, according to Figures 2-5. Esterification reactions were conducted with ricinoleic acid and different alcohols and molar ratios (acid/alcohol) preparations: 2-ethyl-1-hexanol with molar ratio 1:1.2 (Figure 2-BL1) and octanol with molar ratio 1:2 (Figure 3$\mathrm{BL} 2)$. The batch reactor $(200 \mathrm{~mL})$ was maintained at $80^{\circ} \mathrm{C}$ for $24 \mathrm{~h}$ under inert atmosphere of nitrogen. All esterification reactions were catalyzed by boron trifluoride dimethyl etherate ( $0.5 \%$ wt. of acid).

The acetylation reactions were performed with acetic anhydride (1:2) using an alkaline catalyst ( $\mathrm{KOH}, 5 \%$ wt.). The reaction was carried out homogeneously in the liquid phase at $90^{\circ} \mathrm{C}$ for $12 \mathrm{~h}$ under nitrogen atmosphere and intense stirring.

After the acetylation reactions, the mixtures were allowed to cool, transferred to a separator funnel followed by the addition of $100 \mathrm{~mL}$ of ethyl acetate: hexane $(1: 1)$ solution. The $\mathrm{pH}$ of the organic layer was adjusted using a $\mathrm{pH} 5$ buffer solution followed by saturated $\mathrm{NaCl}$ solution. The organic layer was dried over sodium sulfate and filtered. All reaction products were concentrated using a Kugelrohr distiller under vacuum $\left(3 \cdot 10^{-2} \mathrm{mbar}\right)$ at $110^{\circ} \mathrm{C}$ to remove excess alcohol. 
<smiles>Cc1cc(C(C)(C)C)c(O)c(C(C)(C)C)c1</smiles>

(a)<smiles>CCCOC(=O)c1cc(O)c(O)c(O)c1</smiles>

(b)<smiles>[R]c1cccc(O)c1</smiles><smiles>[R]CCCCCCCCCCCCCCC</smiles><smiles>[R]CCCCCCCC#CCCCCCC</smiles>
$\mathrm{R}^{3} \mathrm{C}$ =

(c)

FIGURE 1: Chemical structures of antioxidants: (a) 2,6-di-tert-butyl-4-methylphenol (DBPC); (b) propyl 3,4,5-trihydroxybenzoate (PG); (c) cardanol.

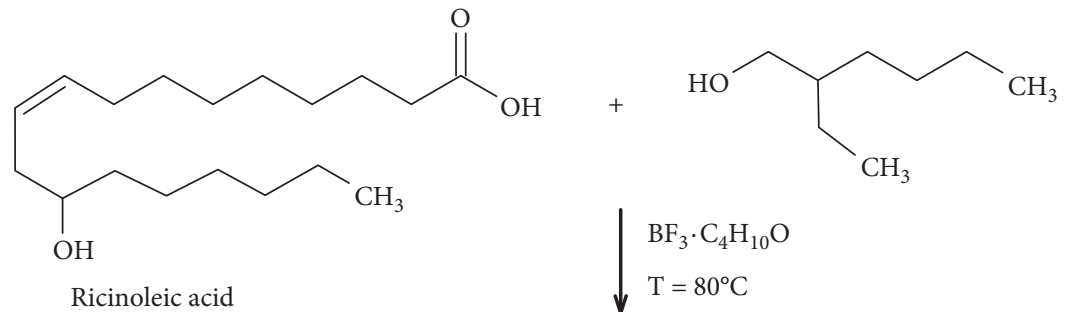<smiles>CCCCCCCCCC(O)CCCCCCCC(O)CCCCCCC(=O)OCC(CC)CCCC</smiles>

$$
\downarrow \begin{aligned}
& \mathrm{KOH} \\
& \mathrm{T}=90^{\circ} \mathrm{C}
\end{aligned}
$$

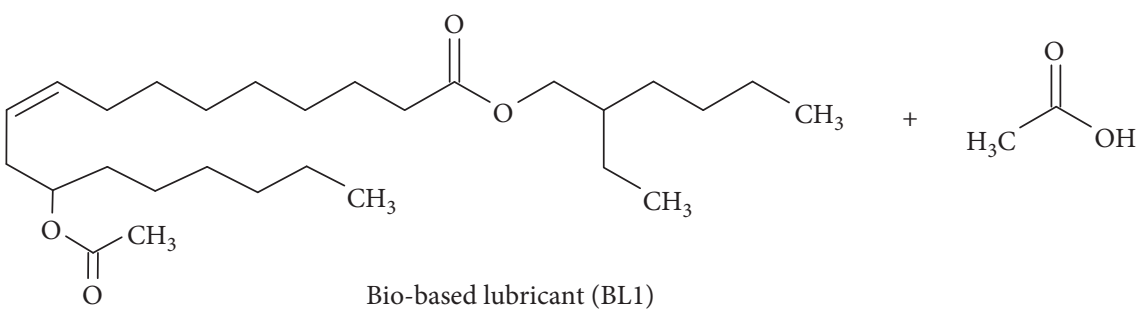

Figure 2: Synthetic route for the bio-based lubricant (BL1).

Samples BL3 (Figure 4) and BL4 (Figure 5) were obtained from 2-ethyl-1-hexanol and octanol, respectively, using first esterification and then hydrogenation followed by acetylation. The esterification and acetylation steps were performed using the same previously described procedure. The hydrogenation step was performed using $2 \%$ wt. of platinum on activated carbon into a stainless steel pressure reactor. After a previous purge with hydrogen, the reactor was charged to 800 to $1.200 \mathrm{kPa}$ of hydrogen. The reactions were stirred for 6 hours at room temperature $\left(\mathrm{ca} .25^{\circ} \mathrm{C}\right)$ until hydrogen consumption was completed. The product was then separated from the catalyst by vacuum filtration through silica and filter paper. The saturated ester was then dried over sodium sulfate and filtered.
After separation, the reaction products were checked for purity by gas chromatography (>95\% wt.). The samples thus obtained were analyzed by GC-FID on a SHIMADZU QP2010 using a (5\% phenyl)-methylpolysiloxane (DB-5) capillary column $(30 \mathrm{~m} \times 0.25 \mathrm{~mm})$ carrier gas helium, and flow rate $30 \mathrm{~mL} / \mathrm{min}$ with the splitless mode.

The products were analyzed by ${ }^{1} \mathrm{H}$ NMR spectroscopy using a Bruker AVANCE DPX 500 spectrometer operating at $500 \mathrm{MHz}$. Samples $(0.050 \mathrm{~mL})$ were dissolved in $0.5 \mathrm{~mL}$ of deuterated chloroform $\left(\mathrm{CDCl}_{3}\right.$; Cambridge Isotope Laboratories, USA) and transferred to an NMR probe ( $5 \mathrm{~mm}$ internal diameter). Spectra were recorded at room temperature with tetramethylsilane (TMS) as internal standard. ${ }^{1} \mathrm{H}$ NMR data are shown in Supplementary Materials (available here) 


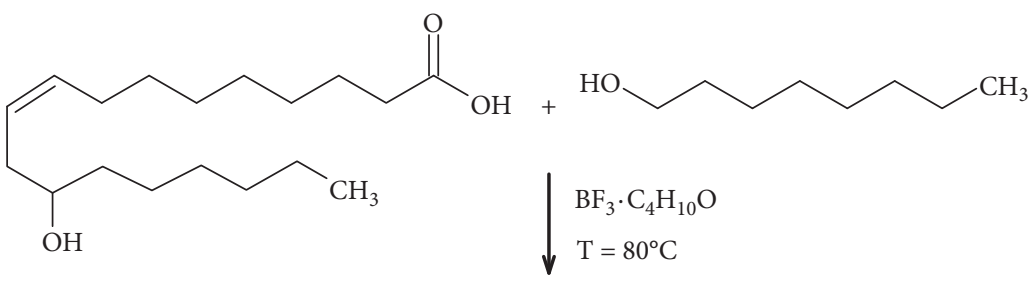

Ricinoleic acid<smiles>CCCCCCCC(=O)OCCCCCCCCC(O)C/C=C\CCCCCCCCCCO</smiles><smiles>CCCCCCCCOC(=O)CCCCCCC/C=C\CC(CCCCCCC)OC(C)=O</smiles>

Figure 3: Synthetic route for the bio-based lubricant (BL2).<smiles>CCCCCCCC(O)C/C=C\CCCCCCCC(=O)OCC(CC)CCCC</smiles>

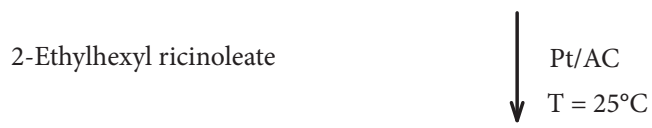<smiles>CCCCCCCCCCCCCC(=O)O</smiles>

2-Ethylhexyl ricinoleate (saturated)<smiles>CCCCC(CC)CO</smiles><smiles>CCCCCCCCCCCC(=O)OCC(CC)CCCC</smiles>

FIgURE 4: Synthetic route for the bio-based lubricant (BL3). 


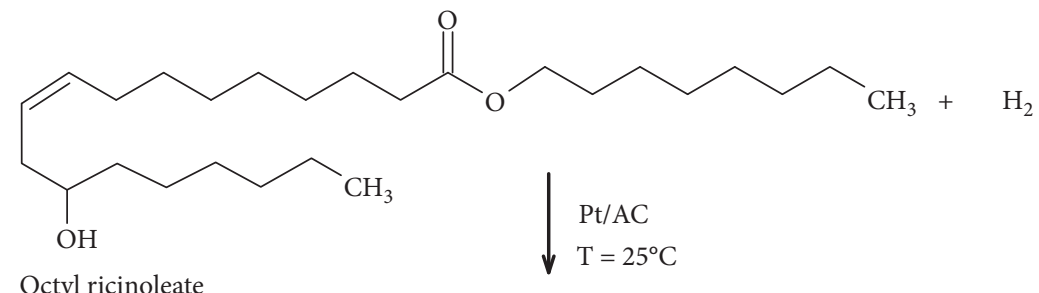

Octyl ricinoleate

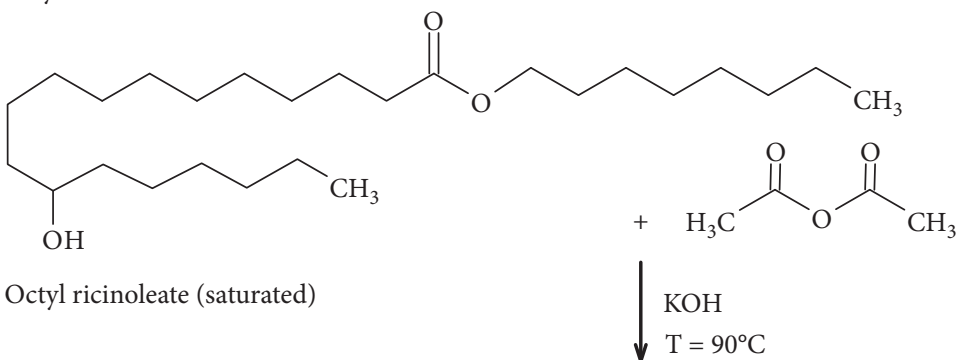<smiles>CCCCCCCCOC(=O)CCCCCCCCCCC(CCCCCCC)OC(C)=O</smiles>

FIGURE 5: Synthetic route for the bio-based lubricant (BL4).

\subsection{Preparation of Unsaturated Cardanol (U-CDN).} Technical CNSL (20.0 g) was used for the process of separation in the chromatography column using silica gel as the stationary phase (Silica Gel 60) by a methodology previously published [18]. The material was eluted with a stepwise gradient of $n$-hexane/ethyl acetate ( $9: 1-7: 3$ by volume). The obtained fractions were analyzed through thin layer chromatography (TLC) and then collected according to their retention factors. The unsaturated cardanol (11.0 g) was separated and then characterized by GC/MS, ${ }^{1} \mathrm{H}$ NMR, and ${ }^{13} \mathrm{C}$ NMR. Saturated cardanol (S-CDN) was obtained from the Sigma-Aldrich and characterized by the same techniques. The data obtained in these analyses are shown in Supplementary Materials (available here).

2.4. Physicochemical Measurements. Specific gravity values were measured at $20^{\circ} \mathrm{C}$ using a DMA 4500 Anton Paar (Austria) according to ASTM D1298. Pour point values were measured according to ASTM D97 using an automatic apparatus ISL_CPP 5Gs (France). This method is routinely used to determine the low temperature flow properties of fluids. It is an important characteristic since it evaluates how well the lubricant will perform in low temperature situations.

The flash point is the minimum temperature at which the liquid produces a sufficient concentration of vapor above it that would form an ignitable mixture with air. The lower the flash point is, the most probable a fire hazard would be. Flash point determination was performed according to ASTM D92/93 based on the Cleveland open cup method measurements using a Koehler apparatus (USA).
Acidity was obtained according to ASTM D664 through the equipment 751 GPD Titrino Metrohm (Switzerland). The automatic titration with potassium hydroxide estimates the total acid number (TAN) as milligrams of $\mathrm{KOH} / \mathrm{g}$ of sample.

Viscosities were measured using an automated Ostwald viscometer (Koehler, USA). Measurements were carried out according to ASTM D445. Triplicate measurements were made, and average values were reported. The viscosity index (VI) that indicates the effect of temperature on the viscosity was also calculated. VI values are obtained directly from the kinematic viscosity values at 40 and $100^{\circ} \mathrm{C}$. The calculations were carried out according to ASTM D2270.

2.5. Accelerated Oxidation Method. The oxidative stability was evaluated using the PetroOXY method (Petrotest, Germany) which was proposed as an alternative to traditional and more laborious methods for measuring the oxidative resistance of fuels and lubricants $[19,20]$. The PetroOXY test is based on oxygen consumption by the sample at specific conditions of temperature and pressure. The test is based on an induction period which is the time necessary from the start of the test to detect a characteristic pressure drop that represents the overcome of the resistance to oxidize [19].

In this method, a sample of $5 \mathrm{~mL}$ is placed into a hermetically sealed chamber at room temperature which is then pressurized to $700 \mathrm{kPa}$ with oxygen. Initially, the chamber is purged 3 times with oxygen to avoid air contamination. After $700 \mathrm{kPa}$ is attained, the temperature of the chamber is progressively increased, until it reaches a set temperature $\left(140^{\circ} \mathrm{C}\right)$. 
Due to the chamber constant volume, the addition of energy will cause pressure to increase. An internal manometer monitors cell pressure. After the maximum pressure is reached and stabilized, any pressure drop indicates that the sample has begun to oxidize [20]. The self-oxidation process typically displays a time during which the overall oxidation reactions are slow, followed by a faster step. The breaking point is characterized by a pressure drop of $14 \mathrm{kPa}$ within 15 minutes in the pressure-time curve. A study on castor oil FAME using both the PetroOXY method and the Rancimat method (traditional technique) was reported by Araújo et al. [21] while monitoring with FTIR spectra to confirm that both methods run through the same oxidation steps. It was also described that the self-oxidation process generally shows a time interval where overall oxidation reactions are slow that is followed by a faster step. The breaking point on the PetroOXY method is then noticed when a characteristic pressure drop is reached.

\section{Results and Discussion}

3.1. Physicochemical Properties of Samples. The properties of the bio-based samples, along with those for the pure castor oil and for mineral oil, are shown in Table 1. The results show that the products obtained using long-chain alcohols (BL1: 2-ethyl-hexanol and BL2: octanol) presented similar viscosity values at both temperatures $\left(40\right.$ and $\left.100^{\circ} \mathrm{C}\right)$. The difference between BL1/BL3 and BL2/BL4 is due to the extrastep of hydrogenation performed before the acetylation reaction, which removes the unstable double bonds from the molecules. The results indicate that chemically modified biobased products with high concentration of unsaturated fats, such as BL1 and BL2, exhibited lower viscosities at $40^{\circ} \mathrm{C}$ and $100^{\circ} \mathrm{C}$ than others with high concentration of saturated fats, such as BL3 and BL4. Pictures of the samples are available in Supplementary Materials (available here).

The viscosity index is used to describe the change of viscosity with temperature for lubricants. The high viscosity index of the samples is an indication that changes in viscosities are minimal at higher temperatures. The results show that the removal of the unsaturation in the molecule chain increases the molecular weight and the viscosity index of the bio-based samples, which has also been reported by Salih et al. [22]. Furthermore, BL1 and BL3 presented higher VI values than BL2 and BL4, which is probably due to the presence of more branching sites, as also reported in previous studies [22, 23].

The pour point of bio-based lubricants is mainly influenced by the efficiency of molecular packing, intermolecular interactions, and molecular weight [24, 25]. A higher level of branching and the presence of double bonds may also influence pour point $[26,27]$. BL1 presented the lowest value of pour point among all samples, which is probably because it is the most branched product and contains unsaturated compounds. Abdullah et al. [28] has also reported that a high level of branching plays a significant role in decreasing the pour point of esters since the branching sites act as a barrier around the molecules and prevents crystallization. The other physicochemical properties for all bio-based samples fall within expected values.
3.2. Accelerated Oxidation Experiments. The pressure profiles for the accelerated oxidation experiments (PetroOXY method) for BL1, BL2, CO, and $\mathrm{MO}$ are presented in Figure 6(a). BL1 and BL2 presented an improvement in the resistance to oxidation when compared to the castor oil results. However, BL1 and BL2 induction times are still not as high as the mineral oil (MO).

Oxidative stability is related to the level of unsaturations present in the vegetable oil and their configuration. Castor oil is composed mainly of monounsaturated fatty acids, in which the double bounds behave as active sites for various reactions including oxidation [29]. A few modifications in the synthetic route of bio-based samples were proposed to improve the oxidative stability of the esters derived from the ricinoleic acid. BL3 and BL4 were thus obtained using the same routes as BL1 and BL2, respectively, but with an extrastep of hydrogenation before the acetylation reactions. The physicochemical properties of these new compounds are also reported in Table 1 . The additional hydrogenation step aims to eliminate the double bounds and thus reduce the number of active sites for oxidation reactions.

The reduction of active sites for oxidation reactions are then confirmed from the results shown in Figure 6(b), in which the oxidative stabilities for both BL3 and BL4 were considerably higher than those for $\mathrm{BL} 1$ and $\mathrm{BL} 2$, respectively. BL3 clearly presented the best oxidative result (induction time of $146 \mathrm{~min}$ ) among all synthetic samples, probably due to its higher degree of branching (esterification with 2-ethyl-hexanol) and saturated chains. The highest improvement of the induction period is presented by BL3 (6.6 times if compared to pure castor oil).

However, we must also note that some physicochemical properties of BL3 and BL4 changed when compared to the nonhydrogenated samples. Hydrogenated products presented higher viscosity and higher pour point (Table 1). Isbell et al. [30] have also reported that the hydrogenation process affects the pour point quality while significantly improving the oxidative stability for acetylated ricinoleic ester. Furthermore, the induction time for BL3 was much higher (146 min) than the values obtained for both the castor oil and the mineral oil samples (22 and $44 \mathrm{~min}$, respectively).

3.3. Accelerated Oxidation of Samples Doped with Antioxidants. In a previous study, Araújo et al. [20] reported a rank of antioxidants effectiveness for castor oil FAME, showing that PG and DBPC, in this order, presented the best performances. In this study, since BL3 has shown the highest resistance to oxidation when compared to the mineral oil, this sample was doped with four different antioxidants (PG, DBPC, S-CDN, and U-CDN) at $4,000 \mathrm{mg} / \mathrm{kg}$ and compared to mineral oil doped with DBPC at the same concentration, as shown in Figure 7. The antioxidants clearly increased the induction times with respect to the original BL3 sample without additive (Figure 6(b)). The BL3 sample doped with propyl gallate (PG) and with saturated cardanol (S-CDN) showed the highest induction times. 
TABle 1: Physicochemical properties of bio-based lubricants, castor oil and mineral oil.

\begin{tabular}{|c|c|c|c|c|c|c|c|}
\hline \multirow{2}{*}{ Samples } & \multirow{2}{*}{ Specific gravity $\left(\mathrm{g} / \mathrm{cm}^{3}\right)$} & \multirow{2}{*}{ Pour point $\left({ }^{\circ} \mathrm{C}\right)$} & \multirow{2}{*}{ Flash point $\left({ }^{\circ} \mathrm{C}\right)$} & \multirow{2}{*}{ TAN (mg.KOH/g) } & \multicolumn{2}{|c|}{ Viscosity (cSt) } & \multirow{2}{*}{ Viscosity index } \\
\hline & & & & & $40^{\circ} \mathrm{C}$ & $100^{\circ} \mathrm{C}$ & \\
\hline Castor oil & 0.9582 & -15 & 286 & 1.080 & 261.3 & 19.60 & 84 \\
\hline BL1 & 0.9033 & -42 & 264 & 0.021 & 17.6 & 4.31 & 159 \\
\hline BL2 & 0.9138 & -36 & 258 & 0.025 & 18.3 & 4.33 & 152 \\
\hline BL3 & 0.9120 & -27 & 268 & 0.018 & 26.0 & 5.57 & 161 \\
\hline BL4 & 0.9084 & -18 & 260 & 0.015 & 38.4 & 7.29 & 157 \\
\hline Mineral oil & 0.8931 & -33 & 160 & 0.001 & 19.8 & 4.12 & 108 \\
\hline
\end{tabular}

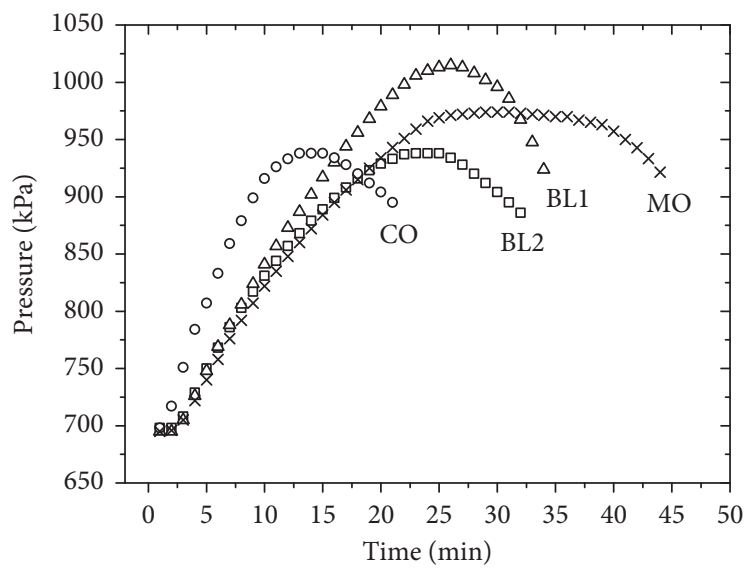

(a)

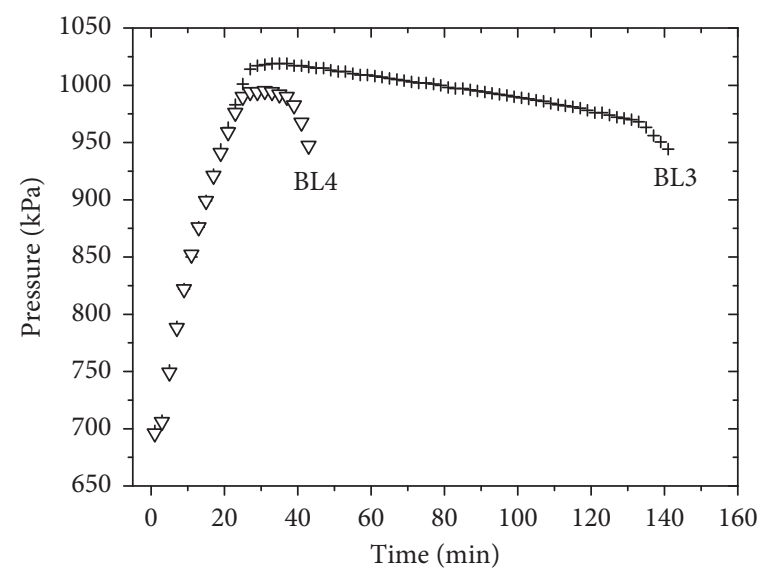

(b)

Figure 6: Pressure profiles for accelerated oxidation experiments at $140^{\circ} \mathrm{C}$ with samples. $\bigcirc, \mathrm{CO} ; \times, \mathrm{MO} ; \Delta, \mathrm{BL} 1 ; €, \mathrm{BL} 2 ;+, \mathrm{BL} 3 ; \nabla, \mathrm{BL} 4$.

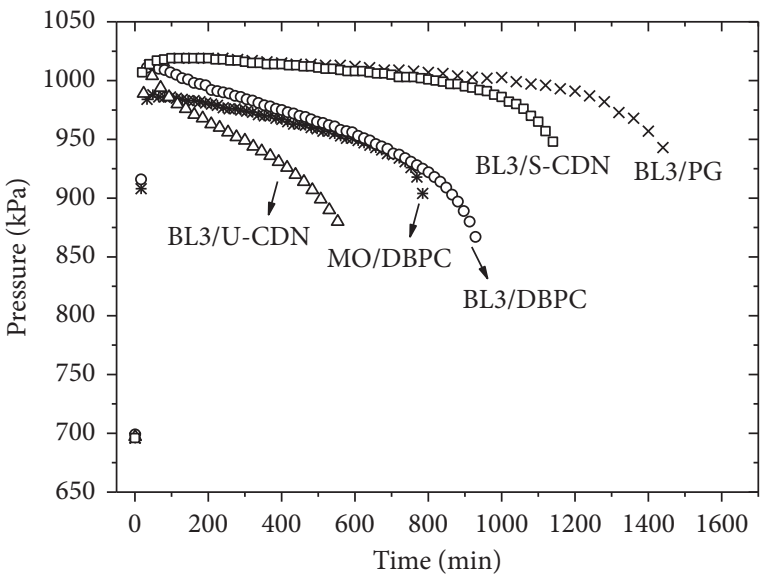

Figure 7: Pressure profiles for accelerated oxidation experiments at $140^{\circ} \mathrm{C}$ with samples of BL3 doped with $4000 \mathrm{mg} / \mathrm{kg}$ of four antioxidants (U-CDN, S-CDN, DBPC, and PG) and for mineral oil doped with DBPC $(4000 \mathrm{mg} / \mathrm{kg})$.

The results of the experimental BL3 induction times with increasing antioxidants concentrations (between 0 and $5000 \mathrm{mg} / \mathrm{Kg}$ ) are shown in Figure 8. The induction times increased with the addition of antioxidants, as expected [31-33], and that PG and S-CDN, in this order, showed consistently the best performances to improve the oxidative stability of the bio-based product (up to 10 times when compared to the fresh sample). Pictures of the BL3 sample

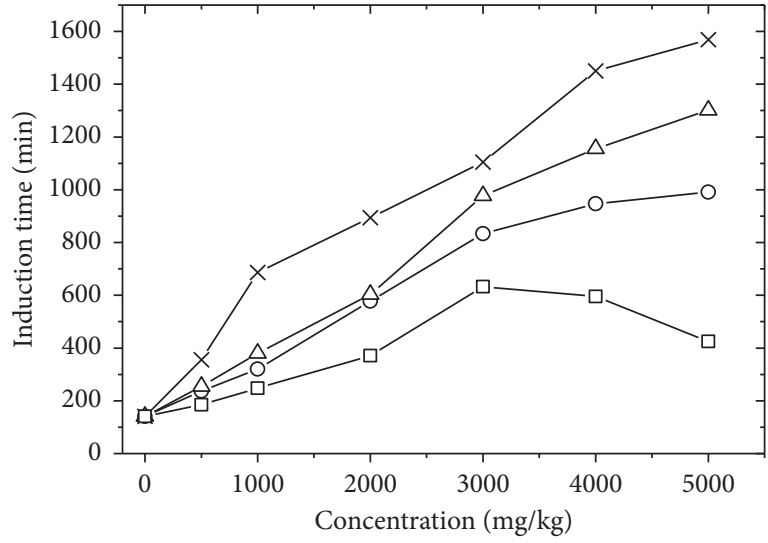

FIgURE 8: Experimental induction times of BL3 as a function of antioxidants concentrations. $\square, \mathrm{U}-\mathrm{CDN} ; \triangle$, S-CDN; $\bigcirc, \mathrm{DBPC}$; $\times$, PG.

doped with four antioxidants (DBPC, PG, S-CDN, and $\mathrm{U}-\mathrm{CDN}$ ) at $5000 \mathrm{mg} / \mathrm{Kg}$, before the oxidation experiments, are shown in Supplementary Materials (available here). No significant change was observed for the color of the doped samples when compared to the nondoped sample, except for the sample doped with U-CDN.

The same procedure was applied to sample BL4 (sample obtained using 1-octanol at the esterification step), with results shown in Figure 9. Again, increased induction times are observed with increasing antioxidants concentrations, 


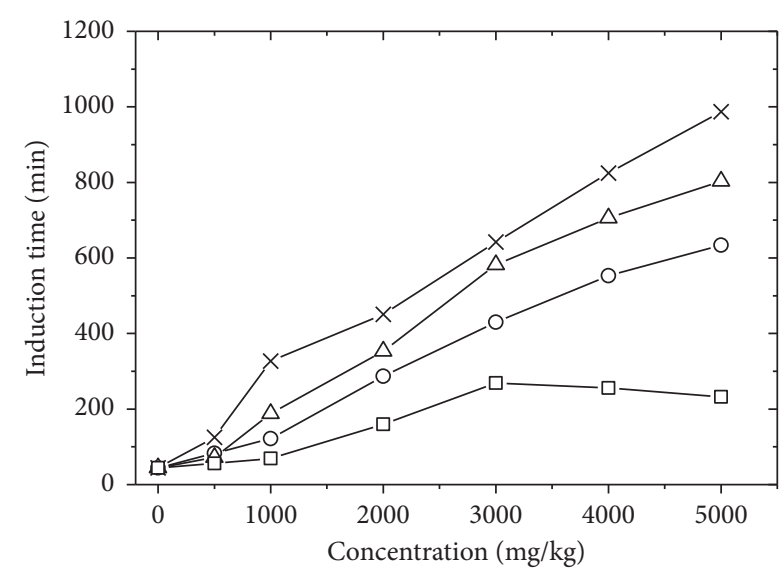

Figure 9: Experimental induction times of BL4 as a function of antioxidants concentrations. $\square, \mathrm{U}-\mathrm{CDN} ; \triangle, \mathrm{S}-\mathrm{CDN}$; $\bigcirc, \mathrm{DBPC}$; $\times$, PG.

with similar behavior of the different antioxidants (PG and $\mathrm{S}-\mathrm{CDN}$ showing the best performances).

According to Figures 8 and 9, the induction times when using the saturated compound (S-CDN) are consistently higher than those for the unsaturated compound (U-CDN), for both BL3 and BL4 at any doping concentration. A maximum value was observed for both biolubricants doped with unsaturated cardanol. This fact is linked to the loss of activity of phenolic antioxidants at high concentrations which start to behave as prooxidants by taking part in the initiation of the oxidative reactions [34].

The antioxidant activity of saturated cardanol (S-CDN) and unsaturated cardanol (U-CDN) has been confirmed in previous studies for biodiesel samples [17, 35-37]. Through other methods of analysis, these studies showed that the addition of phenolic compounds derived from CNSL contribute to the increase of the oxidative stability of bioproducts, which present very similar properties to the samples evaluated in this study. Phenolic compounds such as cardanol may be classified as primary antioxidants or chain breaking antioxidants, which react like the peroxide radicals or hydroperoxides formed during the oxidation process, interrupting the propagation reaction. In the process, they form inactive products, unable to restart the oxidation of the bio-based samples. The action of a phenol as a primary antioxidant occurs, mainly, through the donation of a radical hydrogen of the phenolic hydroxyl that rapidly reacts as the free radical formed by oxidation, a process called free radical scavenging [38].

It is also important to highlight that other factors may interfere in the evaluation of the oxidative stability of the bio-based lubricant and consequently in the action of the antioxidants. Temperature, light, moisture presence, metal ions, and prooxidant agents are factors that may accelerate the oxidative process, contributing to the reduction of the oxidative stability of the oil. On the contrary, some compounds present in the bio-based samples may exhibit a positive synergistic interaction with the added phenolic compounds contributing to the enhancement of the antioxidant action.

\section{Conclusions}

The oxidative stability of different bio-based samples was evaluated using an accelerated oxidation method and compared to a commercial mineral oil. The chemical modifications that were implemented revealed that the acetates samples, which were obtained from ricinoleates with and without hydrogenation, improve the oxidative stability up to 6 times when compared with pure vegetable oil.

The chemical modifications proposed for BL3 samples (esterification using 2-ethyl-1-hexanol), including hydrogenation and acetylation steps, improved the oxidative stability of the bio-based product due to the reduction in the active sites for oxidation reactions and increased branching of the obtained bio-based molecules.

This study also demonstrates that both saturated and unsaturated cardanol are able to significantly extend the oxidative stability of samples. Among the four studied antioxidants, propyl gallate and saturated cardanol exhibited the best performances to increase the oxidative stability of the bio-based samples, regardless of the applied concentration.

\section{Data Availability}

The pressure time and induction time data used to support the findings of this study are included within the article. The chemical characterization of data is included within the supplementary information file.

\section{Conflicts of Interest}

The authors declare that they have no conflicts of interest regarding the publication of this paper.

\section{Acknowledgments}

The authors wish to thank financial and logistic support provided by Petrobras (Petróleo Brasileiro S.A.), CNPq (Conselho Nacional de Pesquisa e Desenvolvimento Científico), and FUNCAP (Fundação Cearense de Apoio ao Desenvolvimento Científico e Tecnológico).

\section{Supplementary Materials}

The nuclear magnetic resonance (NMR) data of the biobased samples obtained in this study (item I) and of the antioxidants obtained from Cashew Shell Nut Liquid (item II) are included. Pictures of some samples are shown in item III. In III(a), the synthesized bio-based samples (BL1-BL4) are compared with mineral and castor oils, while four different antioxidants used for doping one of the samples (BL3) are compared in III(b). (Supplementary Materials)

\section{References}

[1] W. J. Bartz, "Lubricants and the environment," Tribology International, vol. 31, no. 1-3, pp. 35-47, 1998.

[2] A. Willing, "Lubricants based on renewable resources-an environmentally compatible alternative to mineral oil products," Chemosphere, vol. 43, no. 1, pp. 89-98, 2001. 
[3] L. Lazzeri, M. Mazzoncini, A. Rossi et al., "Biolubricants for the textile and tannery industries as an alternative to conventional mineral oils: an application experience in the Tuscany province," Industrial Crops and Products, vol. 24, no. 3, pp. 280-291, 2006.

[4] H. Wagner, R. Luther, and T. Mang, "Lubricant base fluids based on renewable raw materials: their catalytic manufacture and modification," Applied Catalysis A: General, vol. 221, no. 1-2, pp. 429-442, 2001.

[5] J. A. C. da Silva, A. C. Habert, and D. M. G. Freire, "A potential biodegradable lubricant from castor biodiesel esters," Lubrication Science, vol. 25, no. 1, pp. 53-61, 2013.

[6] J. A. C. da Silva, V. F. Soares, R. Fernandez-Lafuente, A. C. Habert, and D. M. G. Freire, "Enzymatic production and characterization of potential biolubricants from castor bean biodiesel," Journal of Molecular Catalysis B: Enzymatic, vol. 122, pp. 323-329, 2015.

[7] V. Scholz and J. N. da Silva, "Prospects and risks of the use of castor oil as a fuel," Biomass and Bioenergy, vol. 32, no. 2, pp. 95-100, 2008.

[8] S. Z. Erhan and S. Asadauskas, "Lubricant basestocks from vegetable oils," Industrial Crops and Products, vol. 11, no. 2-3, pp. 277-282, 2000 .

[9] S. C. Cermak, J. W. Bredsguard, B. L. John et al., "Synthesis and physical properties of new estolide esters," Industrial Crops and Products, vol. 46, pp. 386-391, 2013.

[10] L. Havet, J. Blouet, F. Robbe Valloire, E. Brasseur, and D. Slomka, "Tribological characteristics of some environmentally friendly lubricants," Wear, vol. 248, no. 1-2, pp. 140-146, 2001.

[11] C. Cecutti and D. Agius, "Ecotoxicity and biodegradability in soil and aqueous media of lubricants used in forestry applications," Bioresource Technology, vol. 99, no. 17, pp. 84928496, 2008.

[12] G. Knothe and R. O. Dunn, "Dependence of oil stability index of fatty compounds on their structure and concentration and presence of metals," Journal of the American Oil Chemists' Society, vol. 80, no. 10, pp. 1021-1026, 2003.

[13] G. Knothe, "Some aspects of biodiesel oxidative stability," Fuel Processing Technology, vol. 88, no. 7, pp. 669-677, 2007.

[14] N. J. Fox and G. W. Stachowiak, "Vegetable oil-based lubricants-a review of oxidation," Tribology International, vol. 40, no. 7, pp. 1035-1046, 2007.

[15] M. Mittelbach and C. Remschmidt, Biodiesel-the Comprehensive Handbook, Martin Mittelbach, Vienna, Austria, 2004.

[16] E. Wang, X. Ma, S. Tang et al., "Synthesis and oxidative stability of trimethylolpropane fatty acid triester as a biolubricant base oil from waste cooking oil," Biomass and Bioenergy, vol. 66, pp. 371-378, 2014.

[17] F. J. N. Maia, C. D. S. Clemente, T. M. B. F. Oliveira et al., "Electrochemical and computational studies of phenolic antioxidants from cashew nut shell liquid," Electrochimica Acta, vol. 79, pp. 67-73, 2012.

[18] D. Lomonaco, F. J. N. Maia, C. S. Clemente, J. P. F. Mota, A. E. Costa, and S. E. Mazzetto, "Thermal studies of new biodiesel antioxidants synthesized from a natural occurring phenolic lipid," Fuel, vol. 97, pp. 552-559, 2012.

[19] A. Neumann, T. Jebens, and V. Wierzbicki, "A method for determining oxidation stability of petrodiesel, biodiesel, and blended fuels," American Laboratory, vol. 40, no. 4, pp. 22-26, 2008.

[20] S. V. Araújo, F. M. T. Luna, E. M. Rola Jr., D. C. S. Azevedo, and C. L. Cavalcante Jr., "A rapid method for evaluation of the oxidation stability of castor oil fame: influence of antioxidant type and concentration," Fuel Processing Technology, vol. 90, no. 10, pp. 1272-1277, 2009.

[21] S. V. Araújo, B. S. Rocha, F. M. T. Luna, E. M. Rola, D. C. S. Azevedo, and C. L. Cavalcante, "FTIR assessment of the oxidation process of castor oil fame submitted to petroOXY and rancimat methods," Fuel Processing Technology, vol. 92, no. 5, pp. 1152-1155, 2011.

[22] N. Salih, J. Salimon, and E. Yousif, "The physicochemical and tribological properties of oleic acid based triester biolubricants," Industrial Crops and Products, vol. 34, no. 1, pp. 1089-1096, 2011.

[23] J. Salimon, N. Salih, and E. Yousif, "Chemically modified biolubricant basestocks from epoxidized oleic acid: improved low temperature properties and oxidative stability," Journal of Saudi Chemical Society, vol. 15, no. 3, pp. 195-201, 2011.

[24] J. Salimon, N. Salih, and E. Yousif, "Triester derivatives of oleic acid: the effect of chemical structure on low temperature, thermo-oxidation and tribological properties," Industrial Crops and Products, vol. 38, pp. 107-114, 2012.

[25] T. A. Isbell, B. A. Lowery, S. S. DeKeyser, M. L. Winchell, and S. C. Cermak, "Physical properties of triglyceride estolides from lesquerella and castor oils," Industrial Crops and Products, vol. 23, no. 3, pp. 256-263, 2006.

[26] W. A. Ahmed, A. Yarmo, N. Salih, M. D. Derawi, M. R. Yusop, and J. Salimon, "Synthesis and lubricity properties analysis of branched dicarboxylate esters based lubricant," Malaysian Journal of Analytical Sciences, vol. 19, no. 1, pp. 106-117, 2015.

[27] H.-S. Hwang, A. Adhvaryu, and S. Z. Erhan, "Preparation and properties of lubricant basestocks from epoxidized soybean oil and 2-ethylhexanol," Journal of the American Oil Chemists' Society, vol. 80, no. 8, pp. 811-815, 2003.

[28] B. M. Abdullah, S. I. Zubairi, H. Z. Huri, N. Hairunisa, E. Yousif, and R. C. Basu, "Polyesters based on linoleic acid for biolubricant basestocks: low-temperature, tribological and rheological properties," PLoS One, vol. 11, no. 3, Article ID e0151603, 2016.

[29] N. Salih, J. Salimon, B. M. Abdullah, and E. Yousif, “Thermooxidation, friction-reducing and physicochemical properties of ricinoleic acid based-diester biolubricants," Arabian Journal Of Chemistry, vol. 10, pp. 2273-2280, 2017.

[30] T. A. Isbell and S. C. Cermak, "Synthesis of triglyceride estolides from lesquerella and castor oils," Journal of the American Oil Chemists' Society, vol. 79, no. 12, pp. 1227-1233, 2002.

[31] N. A. Santos, A. M. T. M. Cordeiro, S. S. Damasceno et al., "Commercial antioxidants and thermal stability evaluations," Fuel, vol. 97, pp. 638-643, 2012.

[32] G. Karavalakis, D. Hilari, L. Givalou, D. Karonis, and S. Stournas, "Storage stability and ageing effect of biodiesel blends treated with different antioxidants," Energy, vol. 36, no. 1, pp. 369-374, 2011.

[33] I. M. R. Fattah, H. H. Masjuki, M. A. Kalam et al., "Effect of antioxidants on oxidation stability of biodiesel derived from vegetable and animal based feedstocks," Renewable and Sustainable Energy Reviews, vol. 30, pp. 356-370, 2014.

[34] M. H. Gorden, "The mechanism of antioxidant action in vitro," in Food Antioxidants, B. J. F. Hudson, Ed., pp. 1-18, Elsevier, Amsterdam, Netherlands, 1990.

[35] F. J. N. Maia, F. W. P. Ribeiro, J. H. G. Rangel et al., "Evaluation of antioxidant action by electrochemical and accelerated oxidation experiments of phenolic compounds derived from cashew nut shell liquid," Industrial Crops and Products, vol. 67, pp. 281-286, 2015. 
[36] M. G. F. Rodrigues, A. G. Souza, I. M. G. Santos et al., "Antioxidative properties of hydrogenated cardanol for cotton biodiesel by PDSC and UV/VIS," Journal of Thermal Analysis and Calorimetry, vol. 97, no. 2, pp. 605-609, 2009.

[37] M. A. S. Rios, F. F. P. Santos, F. J. N. Maia, and S. E. Mazzetto, "Evaluation of antioxidants on the thermo-oxidative stability of soybean biodiesel," Journal of Thermal Analysis and Calorimetry, vol. 112, no. 2, pp. 921-927, 2013.

[38] K. Varatharajan and D. S. Pushparani, "Screening of antioxidant additives for biodiesel fuels," Renewable and Sustainable Energy Reviews, vol. 82, pp. 2017-2028, 2018. 

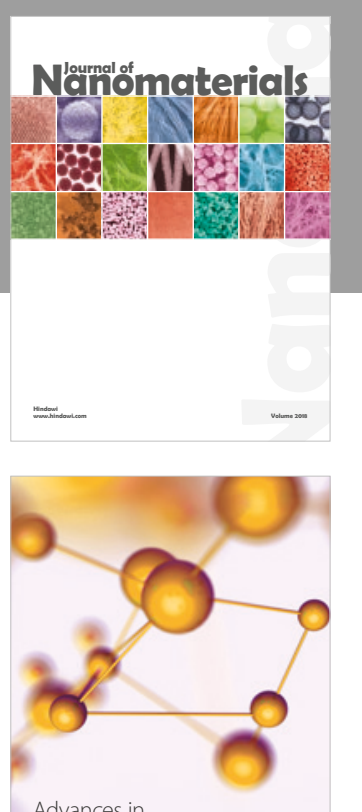

Physical Chemistry
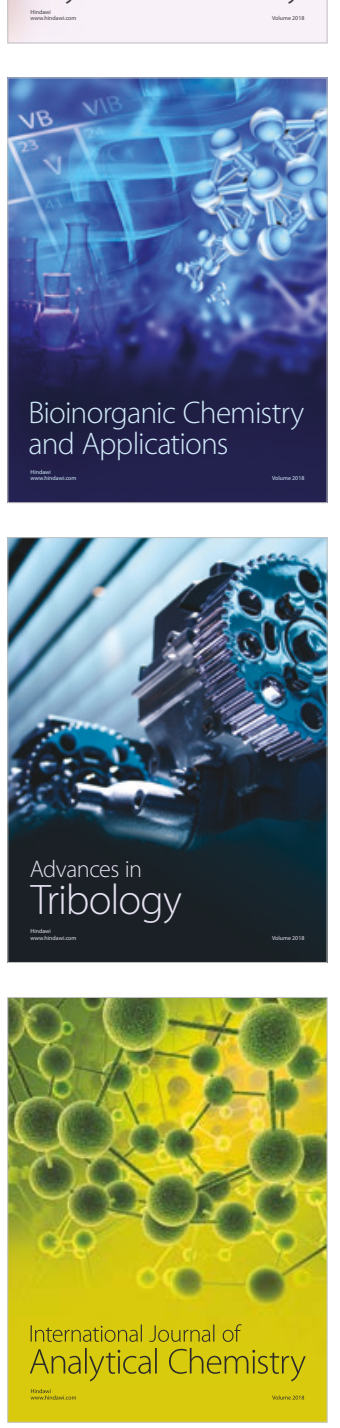

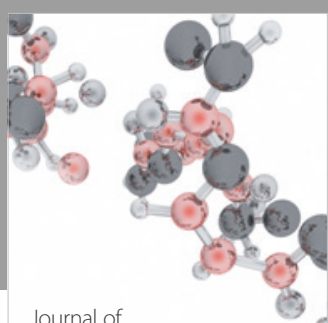

Analytical Methods

in Chemistry

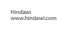

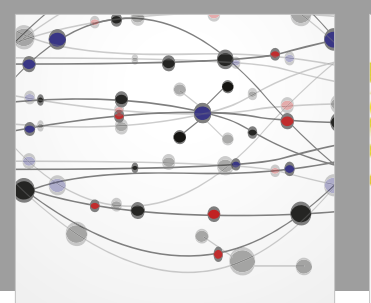

The Scientific World Journal

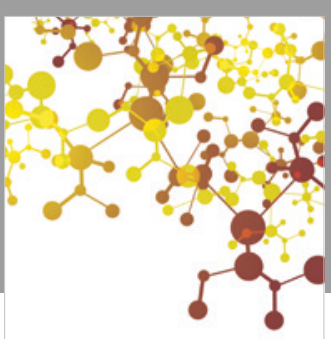

Journal of

Applied Chemistry
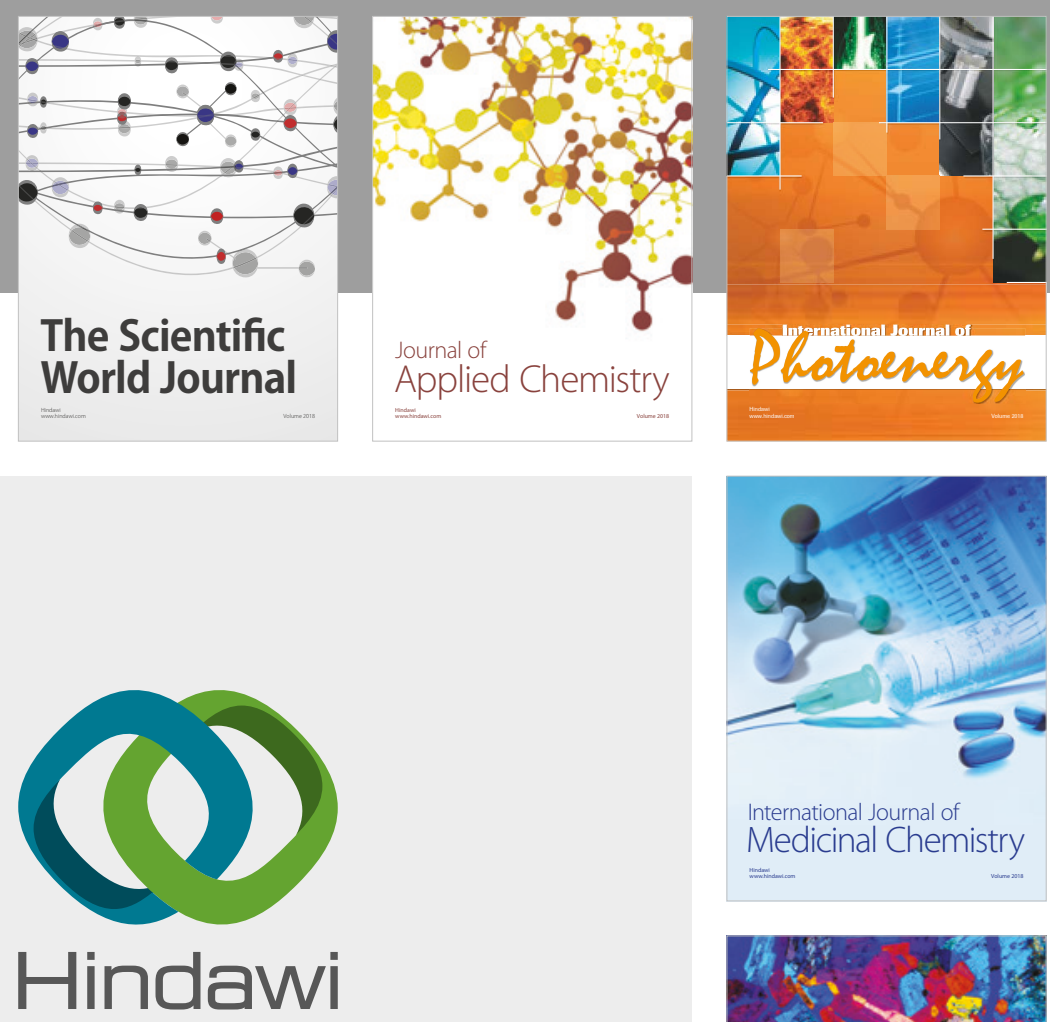

Submit your manuscripts at

www.hindawi.com
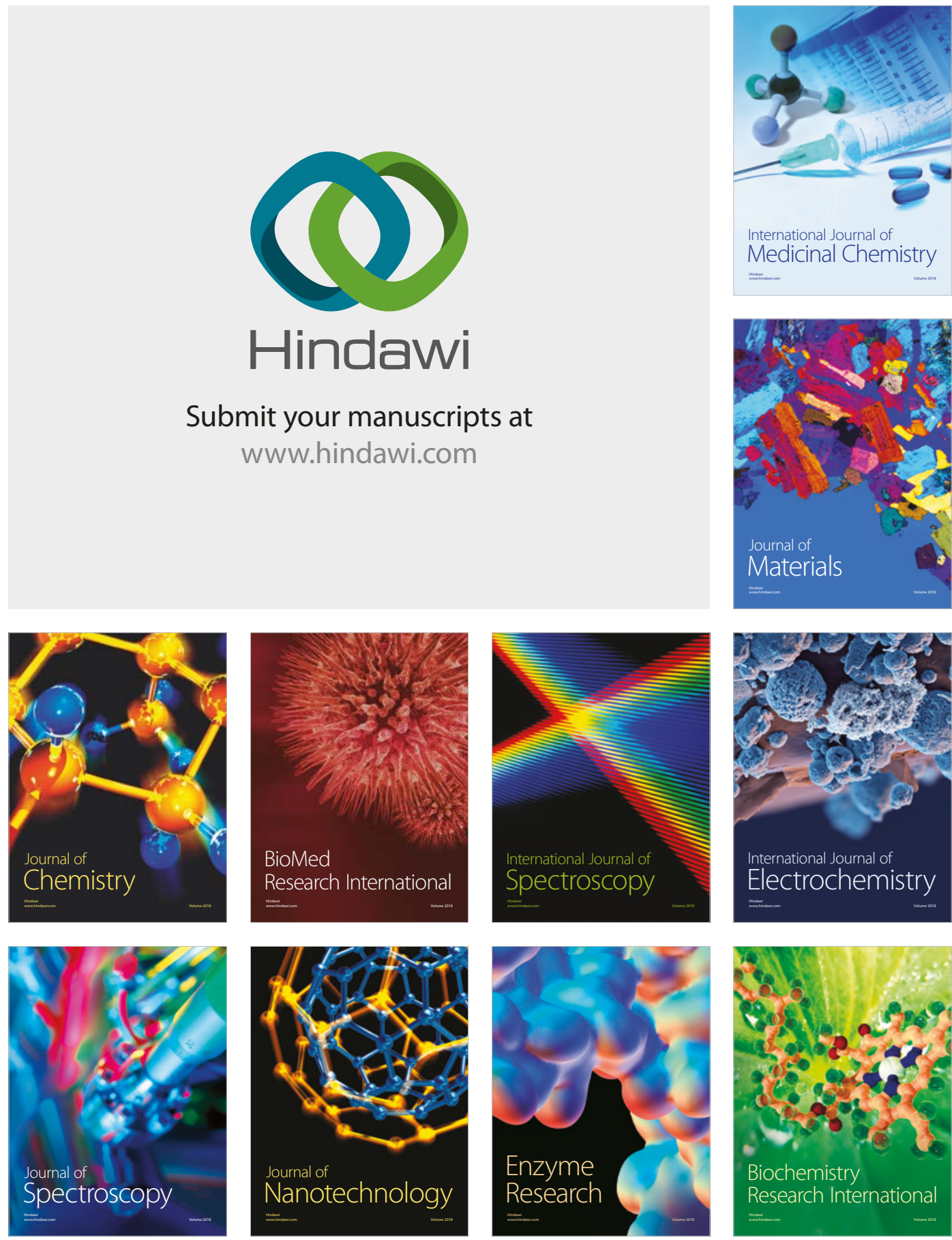
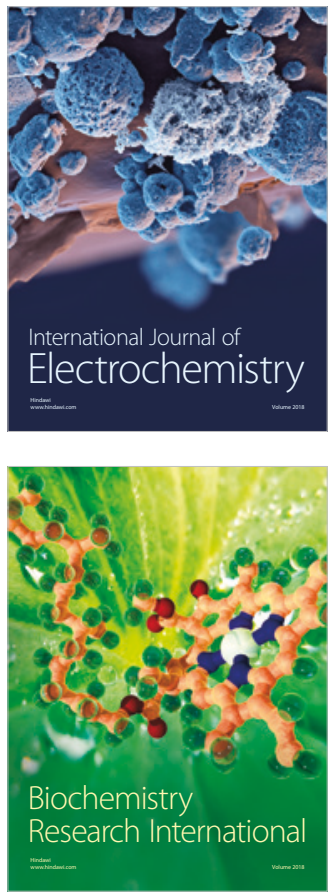